\title{
Concepts for Cargo Ground Handling of Unmanned Cargo Aircrafts and their Influence on the Supply Chain
}

\author{
Dr. Peter, Meincke \\ Institute of Air Transport and Airport Research \\ German Aerospace Center (DLR) \\ Brunswick, Germany \\ Peter.Meincke@dlr.de
}

Leonard Geike

HSB - Bremen City University of Applied Sciences

Aviation Systems Engineering and Management B.Eng.

Bremen, Germany

Leonard.Geike@hotmail.de

\author{
Lukas Asmer \\ Institute of Air Transport and Airport Research \\ German Aerospace Center (DLR) \\ Cologne, Germany \\ Lukas.Asmer@dlr.de \\ Hendrik Wiarda \\ Institute of Air Transport and Airport Research \\ German Aerospace Center (DLR) \\ Brunswick, Germany \\ Hendrik.Wiarda@dlr.de
}

\begin{abstract}
The steadily growing share of air freight transport in the entire logistics industry is mainly due to the three major advantages of speed, safety and reliability. To meet the rising demands, automated transport and delivery processes are increasingly used. As part of the DLR (German Aerospace Center) research project Automated Low Altitude Delivery (ALAADy), a fully automated Unmanned Cargo Aircraft (UCA) with a payload of one ton under the precondition of the Minimum Risk Configuration is being developed in cooperation with seven DLR institutes. As a general area of application, the UCA is appropriate for the so-called "penultimate mile" in the air freight logistics chain, but in order to create optimal integration in the supply chain, the main focus is on the important link of the loading, unloading or reloading processes. The theoretical and practical concepts of this topic were examined within the study under the premise that "No infrastructure exits at destination" in order to obtain the most automated process possible for future logistics. Against this background and the still existing logistics problem of the "last mile”, an UCA requires an automated delivery system. An example of this could be a robotic container based on the units of measurement widely used in logistics. It could be used both for inner-city consignments and for the delivery of goods in rough terrain. Our study shows that the interaction between an UCA and an automated robotic container-system solves both problems of the penultimate and the last mile within the logistics chain. Furthermore, the concepts of ground handling and the development of unmanned systems, including their present capabilities, were studied theoretically to design a model representing basic ground handling processes of Unmanned Aircraft Vehicles (UAVs). The intention was to create a base for further research on this matter by targeting the key requirements for ground handling processes of UCAs in the given
\end{abstract}

concepts. We found out that our obtained findings, approaches for an automated turnaround of an UAV can therefore serve as a basis for future analyses in UCA ground handling and last miles logistics.

Keywords - Unmanned Cargo Aircraft; Unmanned Aircraft Vehicle; ground handling; autonomous; supply chain; last mile.

\section{INTRODUCTION}

Automated cargo delivery is one of the civil applications for Unmanned Aircraft Vehicles (UAV) that is often considered to play a significant role for aviation in the future. A new project of the DLR (German Aerospace Center) called Automated Low Altitude Delivery (ALAADy) investigates the application of a very low level flight unmanned aircraft as an innovative approach of cargo delivery [1].

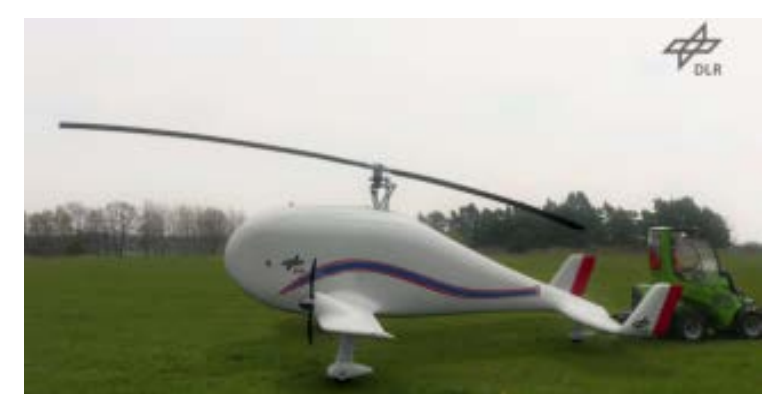

Fig. 1. DLR ALAADy - Automated Low Altitude Delivery - Animated gyrocopter-version. Source: DLR

Below common air traffic, payloads of around one to two tons are carried. This project investigates new safety concepts and 
the economical validity. As part of ALAADy, the Institute of Air Transport and Airport Research is developing concepts for unloading Unmanned Cargo Aircrafts (UCA) and analyzing how these concepts would optimize the classic air cargo supply chain.

The aim of this paper is to identify new concepts how to handle cargo of an UCA at a destination with no cargo infrastructure at all and how to positively impact the air cargo supply chain using them. Reviewing previous studies [2] from 1996 to 2016 indicates that there is no literature about the cargo ground handling of UCAs or even generally about aircraft turnarounds at locations without any (cargo) infrastructure.

Air freight handling in combination with the required documents causes a significant bottleneck factor in air freight transport and reduces productivity. The average consignment transportation time of six days in the traditional air freight transport chain has remained practically unchanged in 20 years [3]. Air freight goods spend around $80 \%$ of their time between sender and recipient on the ground [4]. The clients therefore demand a re-thinking of traditional processes and structures and the development of innovative model solutions for air freight transport [5]. The aim is to offer transport solutions with high reliability and reaction times to reduce delivery times, inventories and costs [6]. The quality of the air freight transport chain is, however, decided on the ground, i.e. in air freight clearance and in the information and communication networking of procedures [7].

Very often, this depends on the available or barely existing cargo infrastructure, and some destinations cannot be reached with freight at all. If infrastructure for cargo handling does not exist at the destination, but - for example - only a landing zone in the mountains, on an island or on a greenfield such as a construction site, major cultural events or even disaster areas, then the use of a UCA opens up a new "last mile" - or rather, a "penultimate mile" [8] - in logistics, for which no means of transport existed so far [9]. For such niches or exceptional situations, UCAs are a suitable solution [10]. How to design concepts for autonomous cargo discharge under these conditions and how links between the last and penultimate mile could look in this context, will be analyzed in the following study.

\section{BASICS OF AIR FREIGHT HANDLING}

Before the described topic can be analyzed, the basics of airfreight handling and the logistics chain have to be explained.

\section{A. Ground Handling in Civil Aviation}

Ground handling is the preparation of an aircraft for the next flight [11]. If the handling of a pure cargo plane is considered, some handling processes of a passenger plane are eliminated or replaced by others, which are the focus of attention, as the safe and efficient loading of freight. The individual process steps (for cargo aircraft only) include:
- Secure the incoming machine (with Chocks, Pylons)

- Ground power supply / refueling

- Unloading or loading the cargo

- Aircraft tow or pushback

- De-icing (if necessary)

Nevertheless, the ground time of a cargo plane is often higher than that of passenger aircraft. This is due, on the one hand, to a different operating model and, on the other hand, to the fact that the loading process occupies a large part of the total ground handling, which is particularly due to the various activities and the cargo to be loaded. In order to facilitate loading, facilities for sorting the cargo, distributing it to a suitable Unit Load Device (ULD), transporting it via the apron and loading it into the aircraft must normally be available at the aerodrome. In doing so, it must be possible to react flexibly to the various aircraft types and types of cargo. Loose cargo is often shipped by hand conventionally, whereas ULDs require lift equipment. It should be noted at this point that the nature of the air cargo determines the transport and handling to a considerable extent [12].

In this paper, the relevant processes for the turnaround of a UAV [13] based on an aircraft are to be considered [14]. A turnaround is the process by which the aircraft is prepared directly for a new flight after landing [15]. According to [12] there are three conceivable approaches to ground handling:

- The aircraft`s own equipment is used

- Technical equipment of the airport is used

- Airport fixed distribution networks with a minimum of mobile facilities are used ("vehicle free apron")

In the present work, only the first approach is consider in order to create concepts for the loading and unloading of a UCA with the requirements of the ALAADy concept. As a supplementary condition to the chosen approach to use only on-board systems for the turnaround [16] should apply: "No (cargo) infrastructure at destination", that is in other words: There is no prior technical equipment or infrastructure for unloading at the destination. On the one hand, this approach is based on covering the widest possible range of use cases with the UCA design together with the used handling technique, and on the other hand, encouraging an maximum autonomous unloading of the UCA. Ultimately, a UCA with a self-sufficient handling technology should bring a maximum of efficiency into the air cargo supply chain.

\section{B. The Air Cargo Supply Chain}

In traditional air freight traffic, which is characterized by the cooperation of freight forwarders, transshipment companies and airlines, there is a need for a shift towards reducedcomplexity logistical structures with increasing integration of 
processes.

The variety of processes that are required between take-off and landing of a cargo aircraft is shown by the logistic supply chain of air cargo handling in Fig. 2.

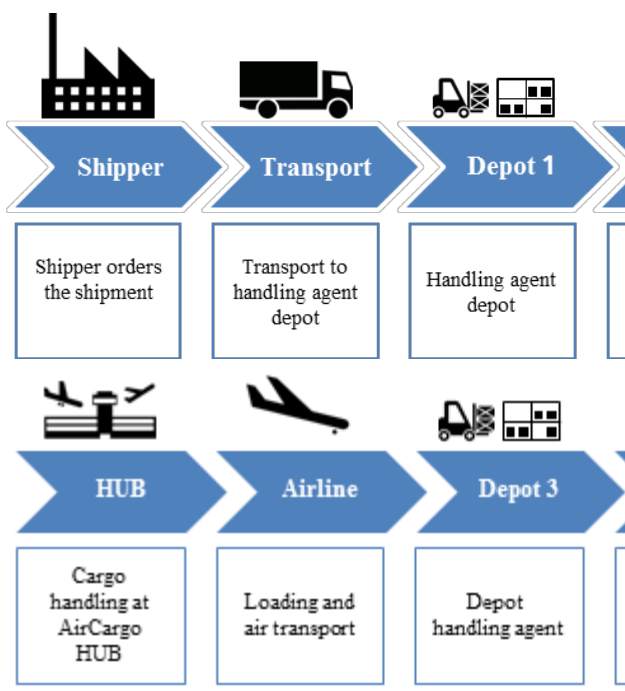

Fig. 2. Logistic supply chain of air cargo handling - Origin part (top) and destination part (down).

These critical elements such as pre-sorting and loading of trucks in depots can hinder timely loading. The individual processes are dependent on a variety of factors such as the length of the paths and available resources in the form of vehicles and labor, with bottlenecks leading to significant delays. Therefore, more sub-steps are to be considered for a successful ground handling than those running next to the aircraft. [15]. belly capacities on scheduled and charter flights. The freight normally comprises standard cargo and a small amount of express products. In continental air freight transport, consignments are often transported between the airports by truck as a replacement for planes due to the lower cost

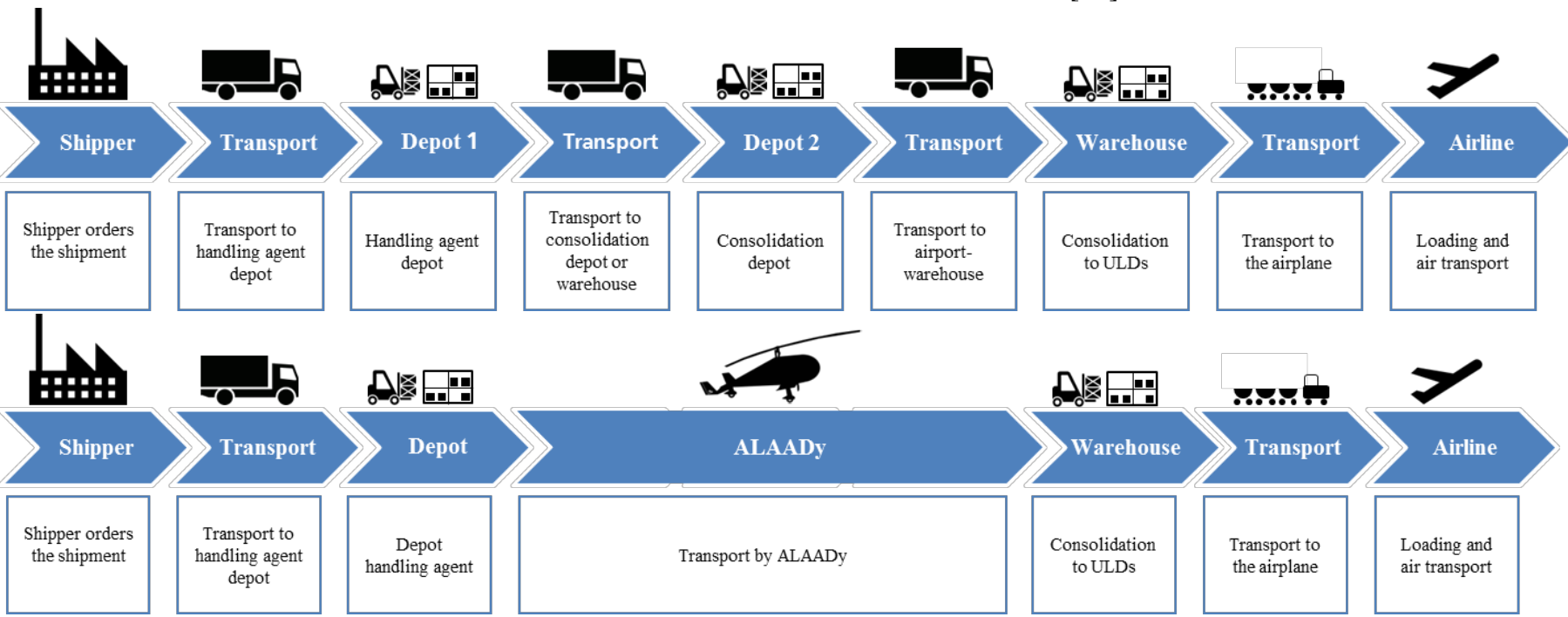

Fig. 3. Air Cargo Supply Chain - Comparison of the origin part (top) and with integration of ALAAdy (down).

In traditional air freight transport chains, the airlines are responsible for transporting the goods from the departure airport to the destination airport (airport-to-airport). The freight airlines operate internationally and offer their airport-to-airport freight services via freight-only aircraft and passenger aircraft also known as Trucking or Road Feeder Service [17].

On the air freight market, forwarders are the salespeople for the airlines' freight capacities, so the airlines normally do not directly market their services. In the transport chain, the forwarders also perform the initial run to the airport, possibly consolidate the consignments, and perform the final run from the destination airport and delivery to the recipient. They also perform additional forwarding and logistical services such as customs clearance. This extends the air freight service into a door-to-door service [18]. structures. This is 
of airfreight in the origin part "above". Depending on the nature of the transport chain and the parties involved, significant time advantages can be gained. In addition, the introduction of an UCA also reduces the number of participants within the process chain, thereby considerably simplifying the overall process.

Most of the use cases studied so far in the project ALAADy (e.g. humanitarian logistics, transport of components between production and assembly sites, spare parts logistics, supply in hard-to-reach areas) have in common that the advantage of the ALAADy system is the fast and flexible delivery of urgently needed goods and parts, which is largely detached from a road or rail network [1]. The condition for this is the possibility to unload cargo after landing on a landing zone and then independently carry out a restart. The system must be minimally dependent on external supply in order to be able to operate independently of existing airfields.

\section{CARgo GRound HANDLING IN CASE OF No INFRASTRUCTURE ON DESTINATION}

The unloading of a UCA from the project specification and the premise of the greatest possible autonomy and independence from conventional airport infrastructure ("No cargo infrastructure at destination") can be divided into the following possible concepts in literature and practice:

- Air cargo drop

- Click-out-and-go

- Using suitable equipment for unloading at destination

- Loading equipment on board

- Mobile loading equipment taken previously to the destination (e.g. with Pioneer-module)

- Unloading by Automated Guided Vehicle (AGV)

- Unloading and delivery by Autonomous Delivery Vehicle/Robot

- Autonomous Container-System included Unit load device (ULD)

In the following, these concepts are discussed with the restriction no existing infrastructure at the destination.

\section{A. Air Cargo Drop}

Dropping cargo is a method especially practiced on military aircraft and in humanitarian relief operations when the ground infrastructure or security situation does not permit landing [20]. For this purpose, goods are attached to parachutes and dropped over the destination. However, ALAADy's current model configuration does not allow air drops without design changes. Furthermore, logistics experts from various aid organizations commented critically on this so-called airdrop option as part of a survey carried out by DLR. It is practiced, however, the effort for the preparation of the relief supplies and preparation of the drop zone is very high and are very application-specific. In addition, it cannot be guaranteed that the aid arrives at the intended recipients, which is why it is not the preferred method of delivery [21]. Nevertheless, the discarding of goods must be considered as a special case, if other variants are not practicable.

There are three main (classic) types of airdrop [22]:

Low-Velocity Airdrop (LVAD) is the delivery of a load involving parachutes that are designed to slow down the load as much as possible.

High-Velocity Airdrop (HVAD) is the delivery of a load involving a parachute to stabilize its fall. One type of HVAD is the LAPES, a Low Altitude Parachute Extraction System, in which the aircraft almost completes a touch-and-go type pattern (without actually touching the ground) and the load is ejected at an extremely low altitude [23].

Free Fall Airdrop is an airdrop with no parachute at all and a Low Cost Aerial Delivery System (LCADS) [24] for a onetime use, stand-alone airdrop system: It consists of a Low Cost Parachute, LC Containers, and platforms. An example of a low-cost aerial system is the current Wings for Aid project "winged cargo delivery box" (Fig. 5), where a simple folding box board box with flaps as a wing is used.

The dropping of cargo must be kept in mind as an option for certain special use cases, but a conceptual change of the previous ALAADy models would be necessary. However, it must be strongly doubted whether integration into the regular supply change can be possible.

\section{B. Click-out-and-go}

In the following, a special type of cargo handling with an aircraft should be mentioned, which will be defined as "clickout-and-go". In other words: Release and deposit the cargo during flight (without direct landing). In this concept, the cargo is usually attached with a fastening mechanism on the outside of the aircraft and is disconnected or "softly" dropped off directly above at the landing point. This method is increasingly being practiced in multicopters or drones in parcel deliveries (DHL Parcelcopter [25], DPD Drone Parcel delivery [26], Amazon Prime Air [27]). Similarly, this is used in helicopters (including the Sikorsky S-64 Skycrane) to avoid direct landing or even engine shutdown or interruption of the flight phase. Since this case is not described in detail in the literature, it should be defined with "click-out-and-go", as it is clearly different from the "Touch-and-go (includes a landing)" [27] as well as the LAPES (see III/A). Under "Click-out-and-go", various differentiated release mechanism (including Modular Aircraft Clip Air [29]) to winch techniques (in helicopters: Helicopter Rope Suspension Technique) with complete loading frame (as Airship Cargolifter [30]) can be summarized. The benefits are obvious: Only a small landing zone is needed at the destination and specialist personnel for "unloading" is not required. At the same time, considerable time savings occur because no general landing of the aircraft is necessary, which eliminates the whole process of turnaround. However, the prerequisite is that the UCA is configured for this unloading technology, i.e. "Vertical take-off and landing” is needed [31].

\section{Using suitable equipment for unloading available at the destination}

Of the listed concepts, the possibilities of "locally available means" and in the following concept "with on-board resources" 
are constructively the simplest to realize. Using suitable equipment for unloading available at the destination means, for example, hand pallet trucks, goods carts or off-road vehicle winches which could be found at the journey's end. It should be possible to handle this equipment by a low-skilled staff. This concept has the disadvantage that the dependence on local conditions is very high, since many influences could hinder a smooth freight handling. Therefore, the design of the UCA should be equipped with tools like roller system or (lifting) ramp to support an effective unloading at the destination).

\section{Loading equipment on board}

Similarly, such simple tools or devices could be integrated as on-board means into the UCA to achieve independence at the destination. These may be portable tools that are carried at the expense of the payload on each flight (e.g. truck-mounted forklift) or tools that are firmly integrated into the structure of the UCA. For example, the floor of the cargo deck in cargo aircraft consists of a combination of roller system and latches, which allow the moving of containers without machine assistance and can firmly lock them during flight. The advantage of these methods is a structurally simple and costeffective implementation as well as high operational flexibility. In addition, all payloads whose size and weight allow manual unloading do not require any special equipment such as pallet trucks, so these methods would be sufficient, for example, for the transport of medicines and other much needed items to people in remote areas. In the case of bulky and heavy items, however, this on-board-concept can be disadvantageous because suitable vehicles and devices must be available at the destination. There is also a need for ground personnel, who may need to be briefed to work safely on the aircraft. Necessary equipment on board for these chase: Lifting ramp, roller system on the cargo hold floor (and/or rolls on the container), mobile winch and truck-mounted forklift.

\section{E. Mobile loading equipment taken previously to the destination (e.g. pioneer modue)}

Alternatively, a "pioneer module" pre-transported by the UAV could set up a "light" infrastructure facility at the destination, for example, by carrying power generators and mobile fueling systems or equipment for a cargo handling (for example truck-mounted fork lifter).

In this way, a destination could be prepared for the cargo handling of a UCA. Although this initially represents a significant financial and logistical overhead, various flights to the same destination would benefit from the existing facilities on the ground. After completion of the handling, or if no further flights are made to this destination, installed equipment must be loaded and transported again. If regular flights are planned, it makes sense to build a minimum infrastructure. If, on the other hand, short-term deliveries to variable destinations are concerned, it is highly unlikely that the time required and the high outlay will make an economic operation possible. Furthermore, for a proper operation of the equipment trained personnel is necessary on site.

\section{F. Unloading by Automated Guided Vehicle (AGV)}

The two following concepts have the advantage that they do not need specialized personnel for unloading. For example, it is conceivable to perform an autonomous unloading of an ALAADy when an Automated Guided Vehicle (AGV) is carried on board in the form of a vertical or mid-level order picker to unload the freight units. Pickers are electrically powered trucks with two pallet forks, which are provided with an additional lift. The speed is typically around $1 \mathrm{~m} / \mathrm{s}$ in passenger traffic environments and higher speeds can be achieved in completely automated areas. A major motivation for using automated guided vehicles, however, is generally the automation of work processes and thus the reduction of manual work [31].

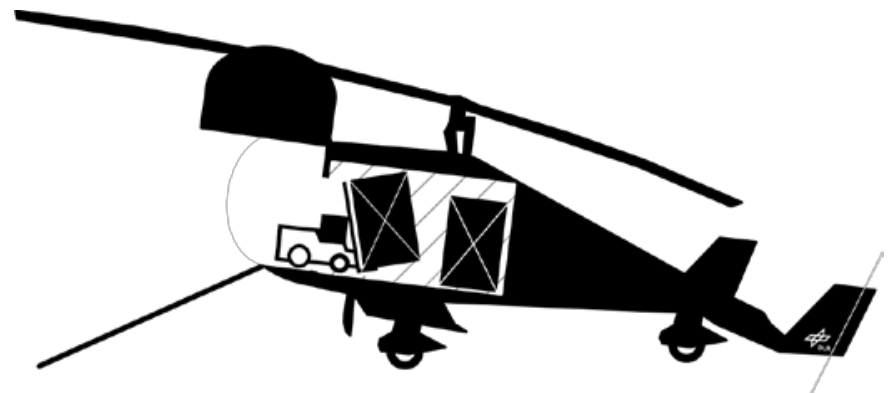

Fig. 4. ALAADy with an Automated Guided Vehicle,

The navigation and spatial orientation is particularly important for AGV, because only if it works completely autonomous, safe and error-free, the system can be operated as desired. There are different approaches, although not all are suitable for the given case: "Operation in a terrain that has no infrastructure”. Navigation with ground guidance or raster navigation or transponders embedded in the ground, magnets or optical grids or even laser navigation will be difficult. In the open air, a navigation via radio bearings with GPS would offer a possibility. Here, however, only an accuracy of $+/-10 \mathrm{~m}$ would be achieved. Accuracy can be improved by a factor of 10 with the Differential Global Positioning System (dGPS).

The problem is the very high weight of the standard AGV, which would exceed the payload of the UCA construction. To solve this, a custom-made solution would be required.

\section{G. Unloading and Delivery by Autonomous Delivery Vehicle}

Another variant of unloading a cargo UAV or aircraft without human resources would be an autonomous robotic vehicle, which leaves the aircraft independently and transports its cargo at the destination to the recipient: Autonomous Delivery Vehicle/Robots (ADV) or Self-Driving Vehicles (SDV) are autonomous robots used for transporting goods: They have the intelligence to make decisions when faced with new or unexpected situations. During the delivery, a variety of different sensors and scanners gather data that is used to avoid obstacles and/or continuously adjust the movement of the tug in order to more the intended path closely follow. This kind of ADV [32] could reduce further processes in the traditional air freight transport chain after the introduction of the ALAADy per se (Fig. 3). This would entail further time and cost potentials, as a more direct and straightforward delivery of the cargo to the recipient can be made. Starship Technologies' ADV and other competitors (e.g. Domino's/Marathon, Dispatch, Marble, Efficiency S.A.S.) are examples of this type of ADV. 
Despite the different fields of application, delivery robots have different characteristics: They are small in comparison to light trucks and hold only a few consignments, in extreme cases only one, and operate battery-electric. They will be tested with the aim of successfully delivering within 20 to 30 minutes. The vehicles seek the way to the receiver autonomously to avoid obstacles automatically. If there are situations in which the self-control of the machine cannot find a way, it passes the control to an operator who commands directly via remote control. The robot moves at 6 to $20 \mathrm{~km} / \mathrm{h}$ and has a secured compartment inside, in which shipments with a total weight of 15 to 150 kilograms [33] can be transported in a radius of 5-20 kilometers. According to the requirements of ALAADy, it should be considered to scale an existing robot up to a ton of weight (including load factor).

The UAV would need a ramp and the robot would have to be anchored (automatically) during the flight to allow autonomous unloading plus delivery at the destination. At present, this combination of unloading an aircraft and simultaneous delivery by a robot has not yet been realized on the market [10]. Currently, only the cooperation of MercedesBenz Vans with Starship Technologies is known, where a prototype of the so-called Mothership Concept is a Sprinter which serves as a mobile loading and transport hub for eight Starship delivery robots [34].

The combination of airfreight unloading and delivery would have crucial time and economic benefits and would be a significant solution to the "last mile" [10] problem in airfreight logistics. This concept should have a high prioritization in following research projects, as this autonomous variant would have a high degree of future viability. Other solution combinations are possible, but it must be assessed whether the benefits achieved outweigh a high design expenditure and decrease of the payload. Disadvantages of this construct are clear: High research and investment costs for market readiness and integration into the logistics chain of the companies.

\section{H. Autonomous Robotic-Container-System and Unit Load Device}

In addition to the infrastructure facilities, the load carriers in airfreight transport represent an important component. Because the use of containers has proven itself (see Tab. I for the benefits and disadvantages [35]), aviation-specific freight containers are used in addition to conventional load carriers such as pallets. Since the existing air cargo containers are based on the respective aircraft type, it is not possible to use these in connection with the ALAADy.

Nevertheless, to achieve the best possible landing space utilization for the ALAADy, it is necessary to develop a corresponding container system. In order to optimally integrate the ALAADy into existing logistics supply chain, it is important that the container system is based on already standardized units of measure of the load carriers. Clue would therefore be a footprint of $120 \mathrm{~mm} \times 80 \mathrm{~mm}$ (EURO pallet) [12]. In reference to the dimension of the load compartment of the ALAADy (300mm x 130mm) it would be possible to transport three container units per flight (Fig. 5).

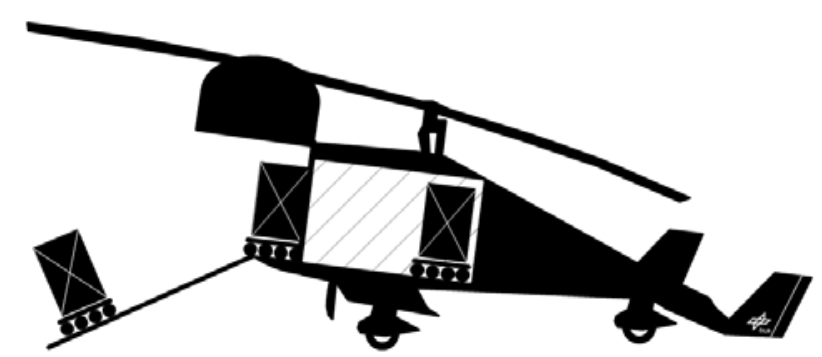

Fig. 5. ALAADy with an Autonomous Robot-Containersystem.

Since the ULD has a considerable influence on the basic loading technology, it also represents an important factor in all previous concepts for the handling of freight (see chapter III/A to $\mathrm{G})$.

While in the previous concept the ULD and the delivery robot were a connected unit, the focus is now on the ULD. Optionally, a "motorized robot base" could serve as an extension and form an autonomous robotic container system. This variant should have a high prioritization in follow-up examinations.

Table I shows the general benefits and disadvantages of Containers in an overview.

TABLE I. GENERAL BENEFITS AND DISADVANTAGES OF CONTAINERS

\begin{tabular}{|l|l|}
\hline \multicolumn{2}{|c|}{ General Benefits of Containers } \\
\hline $\begin{array}{l}\text { Loading and unloading faster and } \\
\text { possible with less staff }\end{array}$ & Time saving aspect \\
\hline $\begin{array}{l}\text { Standardized container units can be } \\
\text { integrated into existing warehouse } \\
\text { technology and automated storage } \\
\text { systems }\end{array}$ & Time saving aspect \\
\hline Less staff around the flying object & Safety aspect \\
\hline $\begin{array}{l}\text { High handling speed makes the use } \\
\text { economical }\end{array}$ & Economic aspect \\
\hline $\begin{array}{l}\text { Container can be loaded before, this } \\
\text { saves time during a turnaround }\end{array}$ & Time saving aspect \\
\hline Weight and Balance can be done easier & Safety aspect \\
\hline $\begin{array}{l}\text { Better securing of cargo possible (in the } \\
\text { container and in the aircraft) }\end{array}$ & Safety aspect \\
\hline Cargo space can be used optimally & Economic aspect \\
\hline $\begin{array}{l}\text { Goods can be made storable by } \\
\text { containers }\end{array}$ & Economic aspect \\
\hline $\begin{array}{l}\text { Use of special containers (e.g. cooling } \\
\text { containers) possible }\end{array}$ & Economic aspect \\
\hline $\begin{array}{l}\text { Protection of the goods against external } \\
\text { influences (e.g. weather or theft) }\end{array}$ & Security aspect \\
\hline $\begin{array}{l}\text { Containers can be waterproof and } \\
\text { floatable }\end{array}$ & Safety aspect \\
\hline $\begin{array}{l}\text { Filling, securing, marking and emptying } \\
\text { the containers is associated with } \\
\text { additional effort }\end{array}$ & Time consuming aspect \\
\hline
\end{tabular}

\section{SIMULATION OF AN UAV TURNAROUND WITHOUT INFRASTRUCTURE AT THE DESTINATION}

In the following, the turnaround of a UCA without infrastructure at the destination is simulated in order to obtain 
general probabilities for the temporal distribution of the handling of these for the handling processes [35]. As already stated in the previous chapter, it should be applied to the approach for handling according to Kazda and Caves [10] that only on-board systems can be used for the duration of the turnaround. In addition, the restriction "No infrastructure at destination" applies. Among other things, the focus is on the freight loading/unloading process. This is based on a semiautomatic process, since it is believed that this type of handling is more likely to be implemented in reality. This would correspond to the given concepts mentioned in chapter III/C to F. (Using suitable equipment for unloading at destination, equipment on board, loading equipment taken previously to the destination and unloading by an AGV).

The combination of a discrete event-driven and agent-based simulation is ideal for mapping the sequence of processes and the involvement of human resources. It examines the case of a direct turnaround, which involves the direct preparation of the aircraft for the next flight. For this purpose, the process sequences of a turnaround from Fig. 6 are converted into an Anylogic ${ }^{1}$ model [36].

\section{A. Ground Handling Processes for a Turnaround}

When defining a coherent turnaround concept, there is the problem that the scope, importance and degree of automation of the individual processes depend significantly on the chosen configuration of the UCA, which is why some framework conditions must be defined below:

- It should be possible to shut down all systems for a longer parking period at the destination, as well as to perform a direct turnaround

- Fully autonomous operation is not required; For individual processes, human labor will be needed

\section{- Some processes need to have a successor process}

Fig. 6 shows an exemplary compilation of necessary ground handling processes for a turnaround. A distinction is made between fully automatic and semi-automatic processes, the latter describing processes with a varying degree of automation and merely indicating that at least one intervention by human labor is necessary. The sequence shown is not absolute and will vary depending on the mission profile, but it will serve as a guide to the simulation and be the basis for the model. The selected process sequence results from the combination of several basic considerations.

On the one hand, there are fixed dependencies between processes, so it is necessary, for example for safety reasons, to shut off the engines before the unloading can begin. Furthermore, under the premise that semi-automatic processes must be accompanied by manpower, it is efficient to run as few such operations as possible in parallel to avoid bottlenecks in available ground personnel [37]. As a final consideration, procedures and sequences of manned civil aviation were

${ }^{1}$ AnyLogic is a multimethod simulation modeling tool developed by The AnyLogic Company. It supports agent-based, discrete event, and system dynamics simulation methodologies. transferred to an unmanned system to provide a rough structure for the individual processes. If only a short stay is planned, which does not require a shutdown, the entire process is shortened.

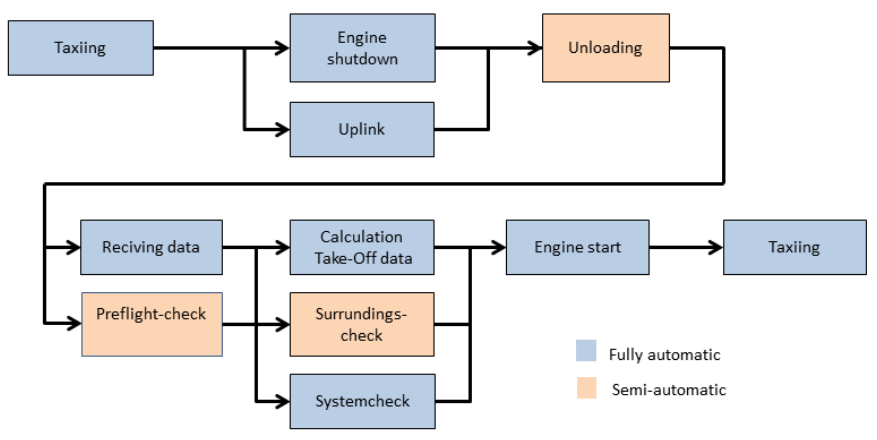

Fig. 6. Ground handling process of an ALAADy turnaround.

\section{B. Creation of the Simulation}

To map the processes in AnyLogic, mostly logic blocks of the Any Logic "Process Modeling Library" [36] were used. This allowed well-defined sequences to be described. In the following, the basic structure of the simulation and some approaches will be explained.

Fig. 7 shows the model transferred to Anylogic for a turnaround. Two parallel process sequences depend on each other and simulate the given entry conditions for the respective processes through hold blocks. To preserve this unified structure, a statechart checks the unlock conditions of the hold blocks. However, since this is a contiguous process, the statechart consists of a single state with an internal transition, which periodically checks the relevant variables.

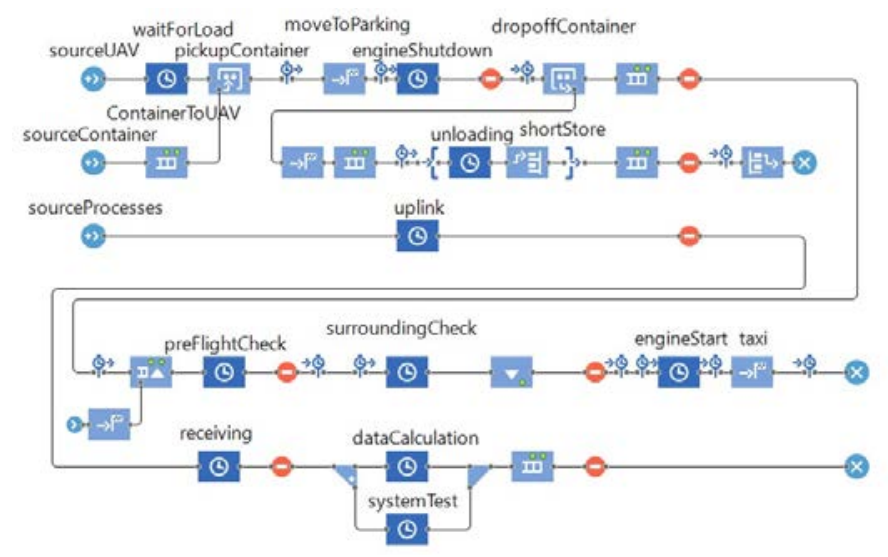

Fig. 7. Simulation of an UAV turnaround without infrastructure at the destination. Source: Own Ilustration in AnyLogic.

The entities generated in the source blocks go through all subsequent logic blocks and end in a connected sink block. The individual processes are each simulated by their own delay block, which keeps agents in an internal queue for a defined period of time and allows purely temporally defined processes already to be mapped. For the semi-automatic processes, however, human labor is needed, which is simulated as a limited resource. For each semi-automatic process, a defined number of resource workers is used through the combination of 
seize and release blocks. In order to map that some processes may be the prerequisite for following, hold blocks at the respective locations interrupt the flow of units and open after the required conditions are met.

When starting the simulation, sourceUAV, after being called by a function, generates a UAVagent that moves to the parking area within a specified time. Ground handling begins at the same time, and simultaneously, a unit is created in sourceProcesses, which serves only to simplify parallel processes and limit the model scope.

The sequence of processes is thus uniquely determined by the arrangement of the blocks and dependencies on previous processes. However, the structure is easy to modify to change sequences or to resolve dependencies.

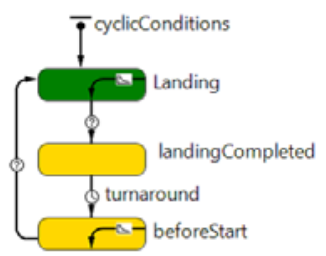

Fig. 8. Statechart for controlling the processes.

The internal transitions in the Landing and beforeStart blocks include cyclic queries for specific events, after which locks in the process flow can be removed (Fig. 8). This is checked against a set of Boolean variables that change their value with the completion of a task. For example, the following condition

"if ( unloaded == true \&\& upl inked == true \&\& systemsChecked == true )

\{

finishUnloading . unblock ( ) ;

uplinkCheck . unblock ( ) ;

unloaded $=$ false ;

uplinked = false ;

systemsChecked $=$ false ;

\}”

checks if the unload, system test, and uplink operations are complete and unlocks the associated hold blocks. Then the variables are reset to their initial value.

At this point, the implementation of the loading and unloading of the cargo has to be addressed, as assumptions had to be made for this simulation. A loading in the form of standardized containers suitable for the cargo space dimensions of ALAADy is required. These containers contain the freight to be transported. Since it should be possible to transport bulky goods which could be mounted in a large container or on a special palette, the number of containers simulated in each run is variable. The most probable case assumes the configuration with three containers, which is why the responsible parameter $n$ Container follows a triangular distribution for integer values with $\mathrm{a}=1, \mathrm{~b}=3, \mathrm{c}=3$. The duration of the loading itself is determined by the required time per container, which is generated independently of the parameter $n$ Container. This is a simplification since there is no simulated correlation between decreasing container number and, as implied, increasing size of individual containers and increasing loading time.

\section{Evaluation of the Simulation Results}

The evaluation of the simulation results is to be understood as creating a basis for further investigations. We wanted to clarify, whether the created model can serve as basis for the following modifications. The selected parameters are only estimates. They are based on analogous processes in other aircraft and reflect the authors' experience. Regardless of the specific application, the parameters listed in Tab. III apply to the simulation.

TABLE II. GENERAL PARAMETERS OF THE SIMULATION

\begin{tabular}{|c|c|c|}
\hline Parameter & Value [min] & Characterization \\
\hline durationTaxi & triangular $(0.5,4,1)$ & $\begin{array}{l}\text { Triangular distribution } \\
\text { with } 3 \text { as most probable } \\
\text { value. Estimated value, } \\
\text { based on the assumption } \\
\text { of predominantly short } \\
\text { rolling distances of } \\
\text { approx. } 200 \mathrm{~m} \text { average }\end{array}$ \\
\hline $\begin{array}{l}\text { duration } \\
\text { Unloading }\end{array}$ & triangular(1,7,3) & $\begin{array}{l}\text { Estimated time required } \\
\text { per container }\end{array}$ \\
\hline $\begin{array}{l}\text { durationEngine } \\
\text { Shutdown }\end{array}$ & 0.8 & $\begin{array}{l}\text { Time from engine } \\
\text { shutdown time }\end{array}$ \\
\hline durationUplink & triangular(0.2,0.7,0.5) & $\begin{array}{l}\text { Data transfer between } \\
\text { UAV and control station. } \\
\text { Depending on the } \\
\text { amount of data and } \\
\text { connection quality }\end{array}$ \\
\hline $\begin{array}{l}\text { durationPreFlight } \\
\text { Check }\end{array}$ & triangular $(1,4,2)$ & $\begin{array}{l}\text { Duration of the preflight } \\
\text { check Reference: } \\
\text { Cessna Citation }\end{array}$ \\
\hline $\begin{array}{l}\text { durationSystem } \\
\text { Test }\end{array}$ & 1 & $\begin{array}{l}\text { Estimated self-test of } \\
\text { computer systems }\end{array}$ \\
\hline $\begin{array}{l}\text { duration } \\
\text { Receiving }\end{array}$ & triangular(1,2,1.5) & $\begin{array}{l}\text { Receiving current flight } \\
\text { plan, weather data and } \\
\text { any further instructions. } \\
\text { Depending on the } \\
\text { amount of data and } \\
\text { connection quality }\end{array}$ \\
\hline $\begin{array}{l}\text { durationSurround } \\
\text { Check }\end{array}$ & triangular(2,4,3) & $\begin{array}{l}\text { Duration of checking the } \\
\text { environment. }\end{array}$ \\
\hline $\begin{array}{l}\text { durationEngine } \\
\text { Start }\end{array}$ & 2 & $\begin{array}{l}\text { Time required to start the } \\
\text { engines }\end{array}$ \\
\hline $\begin{array}{l}\text { durationDataCalc } \\
\text { ulation }\end{array}$ & 0.5 & $\begin{array}{l}\text { Calculate the start data } \\
\text { from received and } \\
\text { measured values }\end{array}$ \\
\hline
\end{tabular}

Due to the stochastic distribution of some input parameters, a large number of turnarounds were simulated within a simulation run in order to minimize random errors. It evaluates a number of 2,000 runs, in which the times of the individual sections and the entire process were measured. 
TABLE III. PARAMETERS OF THE SIMULATION “TURNAROUND”

\begin{tabular}{|l|c|l|}
\hline \multicolumn{1}{|c|}{ Parameter } & Value & \multicolumn{1}{|c|}{ Specification } \\
\hline nContainer & 3 & Number of containers loaded in ALAADy. \\
\hline UAVSpeed & $2 \mathrm{~m} / \mathrm{s}$ & $\begin{array}{l}\text { Speed of the drone during the rolling } \\
\text { process. Estimated, based on the } \\
\text { assumption of uneven ground off the } \\
\text { designated landing stretch. }\end{array}$ \\
\hline WorkerSpeed & $1 \mathrm{~m} / \mathrm{s}$ & $\begin{array}{l}\text { Speed of the personnel with unloading } \\
\text { equipment or AGV on the heavy ground. } \\
\text { Estimate of the mean walking speed. }\end{array}$ \\
\hline
\end{tabular}

Since the simulation of the individual processes is mainly done by delay blocks, which cause a delay of fixed distributed length, the corresponding times must be set individually. These are partly fixed times and in other cases probability distributions, which represent the variability of individual events. From the input values and parameters listed in Tab. III, the results listed in Tab. IV were obtained. The values show both by the large difference between the shortest and longest turnaround, as well as the standard deviation of about $20 \%$ of the mean, a large variability of the values.

TABLE IV. SIMULATION RESULTS FOR TURNAROUND IN MINUTES

\begin{tabular}{|c|c|c|}
\hline & Turnaround normal & nContainer $=\mathbf{3}$ \\
\hline Min & $11.47 \mathrm{~min}$ & $14.94 \mathrm{~min}$ \\
\hline Max & $33.9 \mathrm{~min}$ & $33.20 \mathrm{~min}$ \\
\hline $\mathbf{x}$ & $22.14 \mathrm{~min}$ & $23.66 \mathrm{~min}$ \\
\hline $\boldsymbol{\sigma}$ & $3.83 \mathrm{~min}$ & $2.87 \mathrm{~min}$ \\
\hline
\end{tabular}

$\mathrm{x}$ : mean value, $\sigma$ : standard deviation

Fig. 9 shows an approximate triangular distribution of the results "direct turnaround". If now the number of containers to be loaded is set to a fixed value of three, the scatter of the results is reduced.
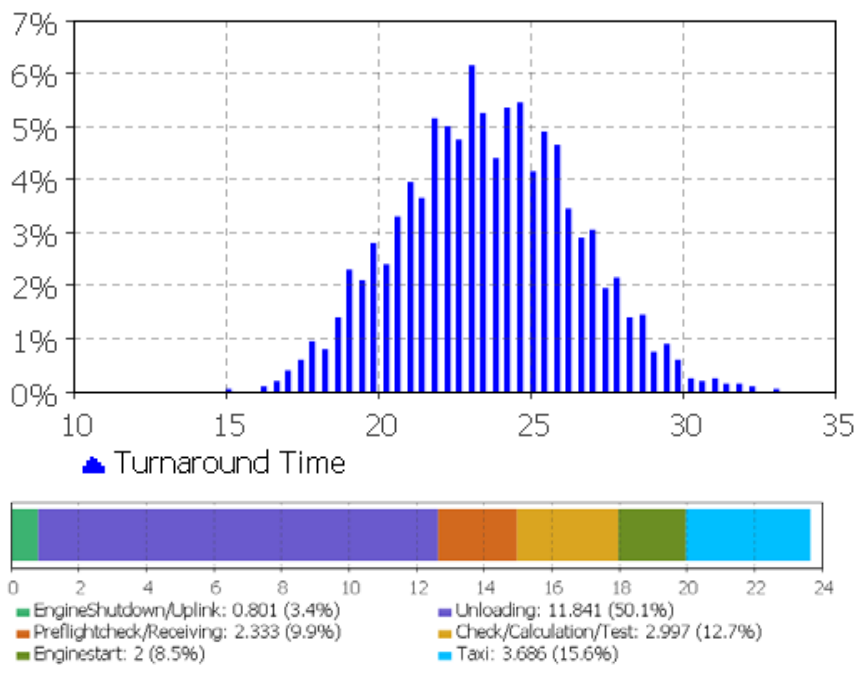

Fig. 9. Graphical representation of the results "turnaround" with nContainer=3; Histogram data (above) and average times (below).
The probability distributions of the parameters are triangular distributions with the values:

$$
\begin{gathered}
\mathrm{a}=\text { minimum value } \\
\mathrm{b}=\text { maximum value } \\
\mathrm{c}=\text { most likely value }
\end{gathered}
$$

The range of the results can theoretically be predicted before the simulation by summing up the minimum and maximum values of the individual process steps. However, these are not taken into account for the following analysis since the probability that all random variables generate their smallest possible value during a turnaround is negligible. Therefore, the average of the generated variables is considered here. The expected value of a triangular-distributed random variable $\mathrm{X}$ is given by:

$$
\mu(X)=\frac{a+b+c}{3}
$$

The sum of $\mu(\mathrm{X})$ results in the expected average total process time. If several processes run in parallel, it is usual and necessary to identify a limiting process that is decisive for this analysis. Due to this predictability of the results, these can be controlled by comparison with expected values calculated from the input parameters. By way of example, the expected values of the parameters for the "use case turnaround" with nContainer $=3$ are summed up in Table $\mathrm{V}$ in order to calculate the total process duration. The calculated expected value differs by $0.87 \mathrm{~min}$ from the time simulated for this case. If the individual expected values are compared with the average times of the respective processes from Fig. 9, the unloading of the cargo can be identified as the reason for this deviation.

TABLE V. CALCULATION OF THE EXPECTED VALUE FROM THE INDIVIDUAL PROCESSES IN MINUTES

\begin{tabular}{|l|c|}
\hline \multicolumn{1}{|c|}{ Parameter } & $\boldsymbol{x}$ in $\mathbf{~ m i n}$ \\
\hline durationTaxi & $2 \times 1.83 \mathrm{~min}$ \\
\hline durationEngineShutdown & $0.8 \mathrm{~min}$ \\
\hline durationUnloading & $3 \times 11 \mathrm{~min}$ \\
\hline durationPreflightCheck & $2.33 \mathrm{~min}$ \\
\hline durationSurroundingCheck & $3 \mathrm{~min}$ \\
\hline durationEngineStart & $2 \mathrm{~min}$ \\
\hline Xges & $\mathbf{2 2 . 7 9} \mathbf{~ m i n}$ \\
\hline
\end{tabular}

This difference can be explained by the additional simulation of resources whose parameters influence the result. Here, the involvement of the resource worker in the process of unloading ensures the distance from the expected value. Taking these differences into account, the simulated results agree sufficiently with the calculated values. This predictability of the results is an indication for the correctness of the simulation. Subject to further validation processes and firm establishment of boundary conditions, the generated simulation can be the basis for a deeper investigation of the soil process. On the basis 
of proven input parameters and with the expansion of the simulation model, a substantiated statement about the actual duration of the turnaround can be made.

Such an expansion of the model can be done by the definition of new processes or the implementation of additional simulation content, such as a dependence of the process time of available resources. Furthermore, dependencies can be specified to determine which contents of a single process are prerequisites for the beginning of another process. By further subdividing processes, various dependencies of this nature can be defined to streamline the order and reduce the turnaround time required.

\section{CONCLUSION}

Here, we illustrated the significance of a UCA for the processes of an air cargo supply chain using the given configurations from the DLR project ALAADy. At the heart of this analysis was freight handling within a turnaround process. It was assumed that the loading and unloading process takes place at a destination that has no (cargo) infrastructure. On the one hand, this premise was intended to promote the investigation of the automation of the cargo unloading process and, on the other hand, to enable coverage of versatile use cases. however, and would provide an important solution to last-mile problems in air cargo logistics. At present, a combination of unloading an aircraft and simultaneous delivery has not been realized in the market yet, and thus would be a novelty. So this concept should have high prioritization in subsequent research projects, since an autonomous variant would be trend-setting.

However, the adaptation of a possible robotic container to the usual units of measurement for ULDs seems indispensable, because only with this step, a smooth handling between different transport systems within the supply chain could be made possible.

Other solutions and combinations are possible, but it is important to assess whether the benefits obtained outweigh the total of the investment. Another promising option could be to revolutionize the last-mile problem on the air cargo supply chain in combination with the "click-out-and-go" concept described above and an autonomous delivery vehicle or robotic-container-system. In a later study, the temporal and economic benefits of these virtual concepts are to be verified on the basis of real processes.

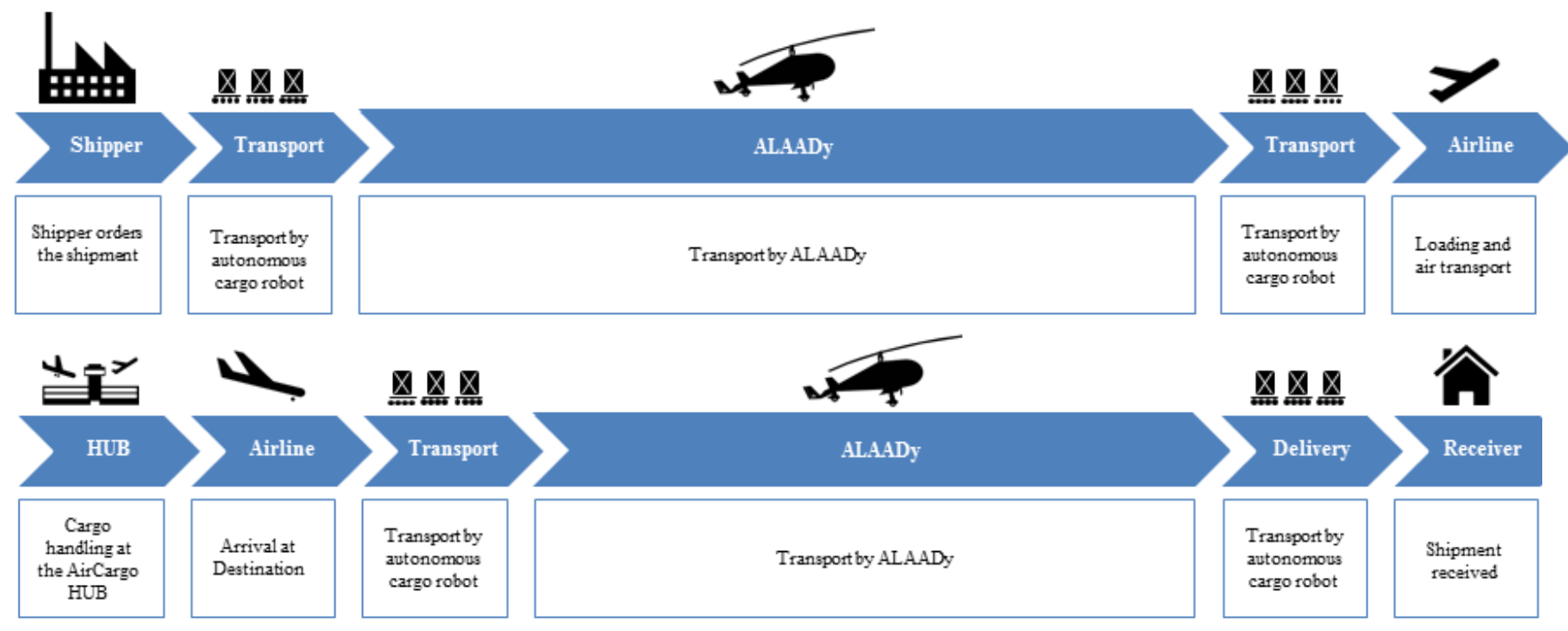

Fig. 10. Air cargo supply chain with UCA “ALAADy” and an Autonomous Robotic-Container-System (Origin and Destinastion with HUBConnection).

As a result, the introduction of UCA like ALAADy (Fig. 3) into the supply chain will provide additional time and cost reduction potential in daily operations by providing a more direct and straightforward delivery of the cargo to the recipient (Fig. 10). To get an idea of the probable handling time, a simulation was created.

The investigation provides a rough framework for a possible turnaround under these conditions. In a later study, further potentials will be verified from real processes. We showed that the combination of air freight unloading and delivery would have significant time and economic benefits,

\section{REFERENCES}

[1] J.C. Dauer, S. Lorenz, J.S. Dittrich, “Automated Low Altitude Air Delivery,” In Deutscher Luft- und Raumfahrtkongress 2016, DocumentID 420129, 2016.

[2] Bo Feng, Yanzhi Li, Zuo-Jun Max Shen, “Air cargo operations: Literature review and comparison with practices," Transportation Research Part C, Available online 24 April 2015.

[3] International Air Transport Association - IATA, "Fact Sheet, IATA efreight,” from http://www.iata.org/pressroom/facts _figures/fact_sheets/ e-freight.htm [14.10.2008].

[4] R. Vahrenkamp, "Geschäftsmodelle und Entwicklungsstrategien von Airlines und Airports in der Luftfracht,“ Arbeitspapier zur Logistik, 2007, p. 23.

[5] H. Heerkens, "Unmanned Cargo Aircraft - From anywhere to everywhere,” Engineering \& Technology Reference Online, 2017, p. 9. 
[6] A. Lennane, "Unmanned aircraft are the future for air cargo 'but we need time to get it right'," Retrieved 8 September, 2017, from https://theloadstar.co.uk/unmanned-aircraft-future-air-cargo-need-timeget-right/

[7] K. Amaruchkul, W.L. Cooper, D. Gupta, “A note on air-cargo capacity contracts,” Prod. Oper. Manage., 20 (1) (2011), pp. 152-162.

[8] G. Warwick, "Is there a commercial market for large unmanned aircraft?” Aviation week. Retrieved 7. October, 2017 from http://aviationweek.com/technology/there-commercial-market-largeunmanned-aircraft

[9] M. P. Collins, “The future market for Large Unmanned Cargo Aircraft in the national airspace system,” Faculty of Lewis University, Aviation \& Transportation, Illinois USA, December 2017.

[10] ZF-Zukunftsstudie 2016, “Die letzte Meile,“ EuroTransportMedia Publisher 2016, p. 40, from http://web-zf-zukunftsstudiede.pixelpark.net/presse-zf-zukunftsstudie-letzte-meile/

[11] International Air Transport Association - IATA, “Ground Handling, International Air Transport Association, October 2013.

[12] A. Kazda, R. E. Caves, “Airport design and operation,” 2. ed. Emerald, Bingley, 2008.of the IEEE 99, 11 (2011), p. 174.

[13] K. Valavanis, G.J. Vachtsevanos, "Handbook of Unmanned Aerial Vehicles,” (Eds.) Springer Publishing 2015.

[14] L. Beier, J. Einig, Ch. Reich, "Entwicklung und Validierung eines Unterstützungswerkzeuges zur Gestaltung von bodenseitigen Logistikund Betriebsprozessen an Fracht-UAV,“ Berufskolleg für Technik und Medien, Mönchengladbach, 2016.

[15] F. Gomez, D. Scholz, "Improvements to ground handling operations and their benefits to direct operating costs," Hamburg University of Applied Sciences, Aero - Aircraft Design and Systems Group, Hamburg, 2009.

[16] Michael Schmidt, “A review of aircraft turnaround operations and simulations,“ Munich Aerospace e.V., Faculty of Aerospace Engineering, Progress in Aerospace Sciences, Volume 92, July 2017, pp. 25-38.

[17] R. Merkert, E.van de Voorde, J. de Wit, ”Making or breaking - Key success factors in the air cargo market,” in Journal of Air Transport Management, Elsevier Publisher, 2017, Available online, 10. February 2017.

[18] P.A. Meincke, A. Tkotz,. "Airports - Types, Functions, Facilities, and Accessibility”, in Introduction to Aviation Management, A. Wald, C. Fay, R. Gleich, Eds., Aviation Management. LIT, Berlin, 2015, pp. 86-126.

[19] T. Boonekamp, G. Burghouwt, "Measuring connectivity in the air freight industry.” in Journal of Air Transport Management, Volume 61, June 2017, pp. 81-94.

[20] J. Sadeck, J. Riley, K. Desabrais, C. Lee, "Low-Cost HALO Cargo Airdrop Systems" in Proceedings of 20th AIAA Aerodynamics Decelerator Systems Conference and Seminar, AIAA Paper 2009-2010, Seattle, WA, May 2009.

[21] DLR - German Aerospace Center, "ALAADy for humanitarian logistic“, Brunswick/Germany 2016.

[22] R. Benney, J. Barber, J.ose McGrath, J. McHugh, G. Noetscher, S, Tavan, "The new military applications of precisi on Air drop systems,"
US Army Research, Development and Engineerring Command, Natick, 26.-29. September 2005.

[23] K. J. Desabrais, J. Riley, J. Sadeck, C. Lee, "Low-Cost High-Altitude Low-Opening Cargo Airdrop Systems," in Journal of aircraft, Vol. 49, No. 1, January-February 2012.

[24] B. Bonaceto, P. Stalker, "Design and Developmentof a New Cargo Parachute and Container Delivery System," in Proceedings of 18th AIAA Aerodynamics Decelerator Systems Conference and Seminar, AIAA Paper 2005-1647, Munich, Germany, May 2005.

[25] DHL, "DHL parcelcopter”, Deutsche Post DHL Group, Bonn 2016, from: http://www.dhl.com/en/press/releases/releases_2016/all/parcel ecommerce/successful_trial_integration_dhl_parcelcopter_logistics_chai n.htm.

[26] DPD, “The DPDgroup Drone Parcel delivery 2.0”, DPDgroup, Aschaffenburg 2016 from https://www.dpd.com/home/insights/ delivery_drones.

[27] Amazon, “Amazon Prime Air,” Seattle/Washington, December 2016, from: https://www.amazon.de/p/feature/vwjfgns3yyjm9uo.

[28] Michael Schmidt, "A review of aircraft turnaround operations and simulations," Munich Aerospace e.V., Faculty of Aerospace Engineering, Progress in Aerospace Sciences, Volume 92, July 2017, pp. 25-38.

[29] EPFL, “Clip Air”, Ecole polytechnique fédérale de Lausanne, 2018, from https://clipair.epfl.ch/home.

[30] Aerospace-technology, “CargoLifter CL160,” Kable Intelligence Limited, London, from: https://www.aerospace-technology.com/ projects/cargolifter/

[31] F. Cakici, M. K. Leblebicioglu, “Control System Design of a Vertical Take-off and Landing Fixed-Wing UAV," IFAC-Papers OnLine Volume 49, Issue 3, 2016, pp. 267-272.

[32] A. Lottermoser, Ch. Berger, S. Braunreuther, G. Reinhart, "Method of usability for mobile robotics in a manufacturing environment," Procedia CIRP 62, 2017, pp. 594 - 599.

[33] DHL PostBot: from http://www.dpdhl.com/de/presse/ pressemitteilungen/ 2017/neuer_zustell_roboter_unterstuetzt_postboten.html

[34] Media Daimler, "Mothership,“ from http://media.daimler.com/mars MediaSite/de/instance/ko/Mercedes-Benz-Vans-investiert-in-StarshipTechnologies-den-weltweit-fuehrenden-Hersteller-vonLieferrobotern.xhtml?oid=15274799

[35] L. Geike, "Simulation und Bewertung von Turnaroundoptionen für UAVs an Landeplätzen mit reduzierten Infrastrukturen,“ Bachelorthesis HSB Hochschule Bremen, City University of Applied Sciences, October 2017.

[36] T. Gudehus, "Logistik - Grundlagen, Strategien, Anwendungen, 3. Edition, Chapter 12.1, p. 427, Hamburg, 2005.

[37] I. Grigoryev, “AnyLogic 7 - New Features Overview”, AnyLogic 2015, from https://www.anylogic.com/resources/libraries/process-modelinglibrary/

[38] W. Tesch, “Turnaround and Ground Handling Aspects,” Presentation for Universität Stuttgart. Praxis-seminar, Stuttgart, 2007. 